\title{
Perspectivas de Estudantes com Deficiências Sobre Facilitadores e Barreiras nas Universidades Públicas de Mato Grosso do Sul ${ }^{1}$ PERSPECTIVES OF STUDENTS WITH Disabilities ABOUT FACILITATORS AND BARRIERS at Public Universities in Mato Grosso do Sul
}

\author{
Etiene Paula da Silva DINIZ² \\ Aline Maira da SILVA ${ }^{3}$
}

\begin{abstract}
RESUMO: O processo de reconhecimento e de participação de estudantes universitários com deficiências tem apresentado desafios que incitam discussóes e investigaçóes. Nesse sentido, este estudo teve por objetivo analisar elementos que se constituem barreiras e/ou facilitadores que, sob a perspectiva de estudantes universitários com deficiências, se apresentam em suas trajetórias de formaçấo acadêmica nas Universidades públicas de Mato Grosso do Sul, Brasil. A pesquisa foi realizada com caráter qualitativo, de modo descritivo exploratório, e valeu-se da técnica de grupo focal. Os resultados foram organizados em eixos temáticos. Como facilitadores da inclusão dos estudantes com deficiências na Educação Superior, os participantes relataram: presença de professores de apoio, intérpretes e monitores; disponibilização de recursos materiais; açóes pedagógicas; adequação de mobiliário; acessibilidade arquitetônica; relações interpessoais positivas com colegas; concepçôes e atitudes positivas dos docentes; funcionamento de núcleo e/ou setor de acessibilidade; e apoio dos familiares. Concomitante e paradoxalmente, foram identificadas barreiras arquitetônicas, urbanísticas, atitudinais, comunicacionais, de informação e pedagógicas. Concluiu-se que a inclusão dos estudantes com deficiências na Universidade enfrenta obstáculos significativos, mas é preciso reconhecer que avanços também podem ser observados e indicam que modificaçóes estáo acontecendo para garantir o direito de acesso, de participação, de aprendizado e de permanência desses estudantes na Educaçáo Superior.
\end{abstract}

PALAVRAS-CHAVE: Educação Superior. Inclusão. Políticas de açôes afirmativas.

\begin{abstract}
The process of recognition and participation of university students with disabilities has presented challenges that incite discussions and investigations. In this sense, the objective of this study was to analyze elements that constitute barriers and/or facilitators, which, from the perspective of university students with disabilities, present themselves in their academic training paths within the public universities in Mato Grosso do Sul, Brazil. The research consisted in a qualitative approach, in an exploratory-descriptive way, and used the focal group technique for data collection. The results were organized into thematic axes. As facilitators of inclusion of students with disabilities in Higher Education, participants reported: presence of support teachers, interpreters and monitors; availability of material resources; pedagogical actions; suitability of furniture; architectural accessibility; positive interpersonal relationships with colleagues; conceptions and positive attitudes of the professors; core operation and/or accessibility sector; and family support. Concomitantly and paradoxically, architectural, urban, attitudinal, communicational, informational and pedagogical barriers were identified. It is concluded that the inclusion of students with disabilities in the university faces significant obstacles, but it must be acknowledged that advances can also be observed and indicate that modifications are taking place in the sense of guaranteeing the right of access, participation, learning and permanence of these students in Higher Education.
\end{abstract}

KEYWORDS: Higher education. Inclusion. Affirmative action policies.

\footnotetext{
${ }^{1}$ https://doi.org/10.1590/1980-54702021v27e0092

${ }^{2}$ Pesquisadora autônoma. Mestre em Educação pela Universidade Federal da Grande Dourados (UFGD). Dourados/Mato Grosso do Sul/ Brasil. E-mail: etienediniz@ufgd.edu.br. ORCID: https://orcid.org/0000-0002-1322-3452

${ }^{3}$ Doutora em Educação Especial pela Universidade Federal de São Carlos (UFSCar). Docente do Programa de Pós-Graduação em Educação da Universidade Federal da Grande Dourados (PPGEdu/UFGD). Dourados/Mato Grosso do Sul/Brasil. E-mail: alinesilva@ufgd.edu.br. ORCID: https://orcid.org/0000-0002-8439-0477
} 


\section{INTRODUÇÃO}

O debate sobre a inclusão das pessoas com deficiências ${ }^{4}$ nas Instituiçóes de Ensino Superior (IES) fortaleceu-se a partir da década de 1990, quando políticas públicas voltaram sua atenção para questóes relacionadas ao ingresso, à permanência e ao sucesso acadêmico desse alunado. No entanto, os dispositivos legais não têm legitimado os direitos da referida população, e a inclusão dos universitários com deficiências na sociedade, particularmente nas esferas educacionais, enfrenta resistências e barreiras que precisam ser superadas, conforme apontam Coutinho (2011) e Tartuci (2014).

Nesse sentido, importa salientar a importância do envolvimento de todos os atores que compóem o cenário das IES, sejam eles gestores institucionais, docentes, técnicos administrativos e discentes, cabendo a todos prover condiçóes para que os estudantes com deficiências possam ingressar, permanecer, pertencer e realizar sua trajetória acadêmica voltada a uma formação cidadã e profissional. Contudo, importa ressaltar que provisóes como essas ocorrem quando, substancialmente, são perpassadas por açóes contínuas coletivas que tenham, como princípios e metas, o respeito à diversidade humana, o reconhecimento das diferenças, a identificação e a eliminação de qualquer tipo de discriminação e a desconstrução de opiniōes preconcebidas (Cury, 2005).

As Universidades públicas brasileiras, portanto, no âmbito da Educação Superior, devem compreender, sob a perspectiva inclusiva, o seu papel social como irradiadoras de conhecimentos e de novas práticas, de modo a comprometer-se com a formação crítica, autônoma, de descobertas e para mudanças sociais, históricas, políticas, econômicas e culturais (Decreto $\mathrm{n}^{\circ}$ 6.949, de 25 de agosto de 2009; Lei no 13.146, de 6 de julho de 2015).

Ao considerar-se a importância de desenvolver estudos sobre o processo de inclusão dos estudantes com deficiências na Educação Superior, a partir da perspectiva dos acadêmicos, a seguinte questão norteou a realização deste estudo: Qual é a opinião dos próprios universitários com deficiências sobre possíveis barreiras e facilitadores encontrados em sua trajetória acadêmica na Universidade?

O objetivo geral foi analisar os elementos que se constituem barreiras e/ou facilitadores que, sob a perspectiva de estudantes universitários com deficiências, se apresentam em suas trajetórias de formação acadêmica no âmbito das Instituiçóes Públicas de Ensino Superior de Mato Grosso do Sul (IPES-MS). Os objetivos específicos foram: a) conhecer as açóes, os serviços e os recursos disponíveis para a sua permanência e a sua formação acadêmica; b) identificar e descrever os desafios por eles enfrentados em sua trajetória acadêmica na Universidade.

\section{Método}

O estudo foi aprovado pelo Comitê de Ética em Pesquisa (CAEE: 87517218.7.0000.5160, Parecer $n^{\circ}$ 2.756.408). Foi realizada uma pesquisa de abordagem qualitativa do tipo descritiva exploratória, utilizando o grupo focal como técnica de pesquisa (Morgan, 1997), por permitir que uma grande quantidade de informaçóes seja levantada e

${ }^{4}$ Optou-se pelo uso da expressão "pessoas com deficiências" em consonância à Convenção Internacional sobre os Direitos das Pessoas com Deficiência (Decreto no 6.949, de 25 de agosto de 2009) e com a Lei Brasileira de Inclusão da Pessoa com Deficiência (Lei no 13.146, de 6 de julho de 2015). 
discutida em profundidade pelos participantes. Como instrumento, foi utilizado um roteiro semiestruturado, previamente submetido à análise de conteúdo e semântica.

O estudo foi desenvolvido nas três universidades públicas de Mato Grosso do Sul: Universidade Estadual de Mato Grosso do Sul (UEMS) - Campus Campo Grande e Campus Dourados; Universidade Federal da Grande Dourados (UFGD); e Universidade Federal de Mato Grosso do Sul (UFMS) - Campus Campo Grande. As três Universidades contam com um setor/núcleo/divisão responsável pela inclusão dos estudantes com deficiências: na UEMS, há o Setor de Inclusão e Diversidade; na UFGD, o Núcleo Multidisciplinar para Inclusão e Acessibilidade; na UFMS, a Divisão de Acessibilidade e Açóes Afirmativas.

Participaram da pesquisa universitários com deficiências das três Universidades citadas que, após o contato e a explanação sobre o estudo, apresentaram sua anuência. No total, foram compostos cinco grupos, sendo dois grupos em duas Universidades e apenas um grupo 5 na terceira Universidade. Participaram da pesquisa 26 estudantes com deficiências, todos acadêmicos da Graduação, 14 do sexo feminino e 12 do sexo masculino. A idade variou entre 18 e 58 anos (com média de 29,3 e mediana igual a 22).

Uma reunião de grupo focal foi conduzida por grupo, com duração média de 1 hora e 30 minutos, em um total de cinco encontros. Todas as reuniōes foram filmadas e, posteriormente, transcritas. Ao considerar-se que a técnica de grupo focal possibilita a troca de informaçóes, um sinal (/) foi utilizado para indicar a interação entre os participantes nos diálogos. A partir da leitura cuidadosa das transcriçóes, foram identificadas as unidades de análise que, em um segundo momento, foram organizadas em dois eixos temáticos.

\section{Resultados E discussão}

A partir da análise dos dados levantados por meio das reunióes de grupo focal com os estudantes com deficiências das Universidades Públicas do Mato Grosso do Sul, foi possível identificar dois eixos temáticos: 1) barreiras impostas aos estudantes com deficiências durante o processo de inclusão na Educação Superior; 2) mecanismos facilitadores da inclusão dos estudantes com deficiências na Educação Superior.

\subsection{Barreiras impostas aOS ESTUdANTES COM DEFICIÊNCIAS DURANTE O PROCESSO DE INCLUSÃo Na EdUCAÇÃo SUPERIOR}

Foi possível identificar e descrever, a partir da perspectiva dos universitários com deficiências, a presença das seguintes barreiras que dificultam o processo de inclusão desses alunos na Educação Superior: arquitetônicas, urbanísticas, atitudinais, comunicacionais, de informação e pedagógicas.

Em relação às barreiras arquitetônicas, alguns participantes citaram: ausência de piso tátil, banheiros adaptados indisponíveis para a utilização desses estudantes, elevadores que não funcionam por falta de manutenção, blocos de aula distantes uns dos outros, presença de rampas não acessíveis e escadas nos campi investigados, conforme mostram as falas dos estudantes que seguem:

\footnotetext{
${ }^{5}$ Em uma das Universidades, foi realizado apenas um grupo focal devido ao baixo número de estudantes com deficiências matriculados.
} 
É lógico que faltam muitas coisas, acessibilidade, piso tátil, [...] outra coisa que solicitei é porque eu não posso subir escada. No ano passado o elevador estava com problema e mudaram a sala para baixo, aí esse ano náo, colocaram em cima e está sem verba para arrumar o elevador, se tivesse rampa para mim era melhor [...]. (Grupo B)

No começo eu tive problema com o banheiro acessível, porque lá no meu bloco, eles usavam o banheiro para guardar as coisas, e sempre quando eu queria usar o banheiro estava ocupado ou estava fechado. De tanto brigar, agora está liberado [...]. (Grupo C)

Os resultados dos estudos conduzidos por Almeida e Ferreira (2018) e Castro e Almeida (2014) também apontaram barreiras arquitetônicas encontradas pelos estudantes com deficiências, como o deslocamento interno, o grande número de escadarias e a ausência de rampas com inclinaçáo adequada, as calçadas com pisos inadequados e a carência de banheiros adaptados e de elevadores.

Evidenciou-se, também, a presença de barreiras arquitetônicas no estudo de Garcia et al. (2018). As autoras apontaram, a partir dos relatos dos estudantes com deficiências pesquisados, a presença de calçadas irregulares e com buracos, a falta de piso tátil e os ambientes de difícil acesso devido à falta de sinalização. Nesse sentido, Cantorani e Pilatti (2015) e Poker et al. (2018) também indicaram a escassez de acessibilidade física nas universidades. No estudo de Cabral e Melo (2017), 48\% dos gestores dos núcleos de acessibilidade participantes do estudo informaram inadequação das condiçóes de infraestrutura.

Os achados das pesquisas recentes sobre o tema em questáo evidenciam que a falta de acessibilidade física no campus, percebida pelos participantes deste estudo, não é uma barreira presente apenas nas universidades públicas do Mato Grosso do Sul. Além disso, destaca-se que a falta de acessibilidade foi denunciada (neste estudo e em pesquisas recentes sobre o tema) pelos diferentes atores envolvidos com o processo de inclusão na Educação Superior, ou seja, acadêmicos, gestores e docentes.

As barreiras atitudinais também foram citadas pelos participantes desta pesquisa. Os participantes registraram que o relacionamento com os demais colegas muitas vezes é marcado pelo preconceito, manifestado na exclusão dos alunos com deficiências e no uso de rótulos, assim como no comportamento de recusa ou esquiva no momento de compor grupos para realizar as atividades acadêmicas. Os colegas consideram que o grupo pode ser prejudicado com a presença dos alunos com deficiências, de acordo com as falas dos estudantes a seguir:

Tem pessoas que às vezes são tão ignorantes e falam que aquele banheiro é de cadeirante. Eu falo que eu sei que o banheiro é de cadeirante e também de pessoas com qualquer deficiência. Eles acham que porque está lá o desenho da cadeira de rodas é só de cadeirante. Eu já fui usar e eu falo que independente disso, que é a deficiência. (Grupo C)

Castro e Almeida (2014) e Calheiros e Fumes (2016) também apontaram, em seus estudos, barreiras atitudinais vivenciadas pelos estudantes com deficiências em relação aos colegas de sala e aos professores. Foram mencionados colegas de sala que desrespeitam a deficiência ou a necessidade específica manifestada pelos alunos com deficiências, assim como professores que náo sabem como lidar com as especificidades desses alunos. 
Um resultado obtido neste estudo que merece ser destacado é a reação dos universitários com deficiências frente às barreiras atitudinais. Foi identificado que os estudantes não apenas percebem a existência de tais barreiras, como também, em muitos casos, se engajam em movimentos individuais de resistência. Os participantes relataram situaçóes nas quais esclarecem colegas e professores sobre seus direitos ou, ainda, descreveram momentos nos quais têm a necessidade de demonstrar sua capacidade, apesar de suas especificidades.

Nessa direção, uma das participantes da pesquisa relatou que seus colegas de turma manifestavam atitudes de preconceito pela profissional de apoio que a acompanhava, ao demonstrar a crença de que ela não apenas escrevia o que a estudante pedia, mas também respondia suas provas, de acordo com a fala a seguir:

É bom ter o apoio, e eu tenho, só que é complicado porque as pessoas veem na sala de aula, porque ela é minha mão, ela não é minha mente, e as colegas que estão em volta no momento de prova mesmo é como se ela estivesse dando as respostas e não fosse eu. (Grupo C)

Dados semelhantes foram obtidos no estudo de Silva e Ferreira (2017), no qual uma professora participante afirmou que os estudantes com deficiências não podem obter benefícios por apresentar uma deficiência.

No que diz respeito às atividades em grupo, foi mencionado, pelos participantes, o sentimento de solidão e de tristeza por não serem escolhidos pelos colegas para compor grupos em sala de aula. Atitudes como essa, de preconceito e de exclusão em momentos de formar grupos em sala, também foram evidenciadas no estudo de Castro (2011). Outros participantes ainda relataram que, diante de momentos de preconceito, eles se isolam e ficam retraídos, de acordo com as falas ilustrativas a seguir:

Eu fico quieto no meu canto. Não ligo muito. Ah, não, eu faço a minha parte da escrita normal. Faço o que sobra, normalmente, o relatório (em situaçóes de seminários). (Grupo A)

Então, no momento de grupo, as pessoas ficam achando que eu não vou dar conta, então já ficam aqueles grupinhos todos formados. E eu falei para a professora deixar eu fazer sozinha, ela disse que eu estava me excluindo, eu falei que estava mesmo [...]. (Grupo C)

No meu caso sim, eu sofri bastante preconceito no começo do meu curso por ser deficiente, quase desisti do curso [...]. (Grupo E)

Ainda sobre as barreiras atitudinais, percebeu-se que, segundo o relato dos participantes deste estudo, os professores demonstram duvidar da capacidade dos estudantes com deficiências, ao desmotivar a realização de alguma atividade mais complexa ou até impedir a participação deles, conforme pode ser observado na fala a seguir:

Até nas viagens que tem na universidade [...] eles falaram que náo iam me levar, porque eu tenho problema, eu ia dar trabalho. É como se você estivesse atrapalhando o grupo, entendeu? (Grupo C)

Segundo Moreira (2010), também há relatos dos próprios estudantes com deficiências em que eles manifestam a necessidade de sempre demonstrar suas aptidóes. $\mathrm{O}$ que se 
percebe é que esses estudantes se sentem menores em relação aos estudantes sem deficiência. Também foi identificada a presença de barreiras atitudinais em relação ao atendimento inadequado de parte dos técnicos administrativos, os quais, muitas, vezes negam informaçóes aos estudantes com deficiências, assim como em relação à coordenação, que não garante o suporte necessário e não conversa com o corpo docente sobre as necessidades específicas apresentadas por esses acadêmicos. As falas dos estudantes que seguem são exemplos dessas barreiras:

Mal atendimento. Cara feia, a gente chega lá para falar com eles, pedir uma informação, eles fazem cara feia, perguntam se você náo leu o regulamento [...]. (Grupo A)

Mais uma coisa que eu queria colocar é também a comunicação entre a coordenação dos cursos e os professores, porque, muitas vezes, os professores entram na sala, e eles não sabe que ali tem um(a) aluna(o) que tem uma deficiência [...]. Isso também aconteceu comigo várias vezes [...]. (Grupo B)

Fato semelhante foi indicado no estudo de Magalhães (2016), no qual duas professoras participantes citaram que também não foram informadas pela coordenação de seu curso sobre a presença de alunos com deficiências em sua turma. Em vista disso, barreiras físicas e atitudinais representam obstáculos significativos para os alunos com deficiências nas Universidades, o que dificulta a permanência e o sucesso acadêmico. No entanto, outras barreiras foram apontadas pelos participantes deste estudo.

Quanto às barreiras de comunicação, foi relatado que a dificuldade na comunicação, na maior parte das vezes decorrente do fato de os colegas não fazerem uso da língua de sinais, acarreta sentimento de vergonha por parte dos participantes com deficiências, conforme as falas ilustrativas a seguir:

A minha barreira mesmo é na comunicação, porque como eu sou surdo e a maioria dos estudantes são ouvintes, e eu por ser a minoria às vezes fico com essa barreira. Às vezes em quase todos os lugares que eu chego, as pessoas só falam a língua portuguesa, e eu fico sem saber às vezes o que está acontecendo [...]. (Grupo E)

Eu tenho um grupo de amigos que são tranquilos, mas às vezes eu tenho muita vergonha porque eles não sabem LIBRAS, e eu fico com vergonha [...]. Me sinto bem sozinha, já me acostumei. Eu nunca fiz apresentação, eu tenho vergonha [...]. (Grupo D)

No estudo de Martins (2016), os resultados também indicaram a dificuldade de relacionamento do estudante surdo com os estudantes ouvintes. Nessa direção, um dos participantes mencionou que, embora ele tenha intérprete de Língua Brasileira de Sinais (LIBRAS) nas aulas, poucas pessoas no ambiente universitário têm conhecimento sobre a língua de sinais, dificultando a compreensão e, consequentemente, a permanência do estudante surdo na Educação Superior. Conforme citado nos estudos de Castro e Almeida (2014) e Calheiros e Fumes (2016), a falta de intérprete de LIBRAS na Universidade dificulta a permanência do estudante surdo, pois resulta em escassez de acesso à comunicação, aos processos educativos e à informação.

Além das barreiras de comunicação, as barreiras pedagógicas também foram relatadas pelos participantes. Como exemplos de barreiras pedagógicas, foram citados: os materiais 
utilizados nas aulas não são adaptados de acordo com as necessidades específicas dos estudantes com deficiências; a falta de livros digitalizados dificulta a leitura dos estudantes com baixa visão; a utilização de aparelhos de projeção em sala de aula dificulta o acesso dos estudantes com baixa visão e sensibilidade à claridade. Foi evidenciado o sentimento dos universitários de que cabe a eles o papel de se adaptar à Universidade e não o contrário, conforme apontam as falas ilustrativas que seguem:

Material ampliado, materiais que realmente possam se adequar aos alunos - e náo os alunos se adequar aos materiais, porque o que eu mais percebo é que parece que nós temos que começar a nos adequar à faculdade [...]. (Grupo E)

Eu acho que ela deveria conscientizar, às vezes adaptar mesmo os materiais e utilizar os recursos tecnológicos [...]. (Grupo E)

Eu encontrei dificuldade, por exemplo, em aparelho de projeção, que, às vezes, é muito claro, eu tenho sensibilidade à claridade, não dá para entender as letras [...]. (Grupo E)

Nos estudos conduzidos por Nantes (2012) e Castro e Almeida (2014) também foi mencionada pelos estudantes a falta de formação docente voltada à utilização de materiais e/ou à adoção de métodos inadequados. Silva e Ferreira (2017) também identificaram um exemplo de barreira pedagógica, ao descreverem uma situação na qual um professor transmitiu um vídeo sem som em uma turma da qual fazia parte um estudante cego, sem prever nenhum tipo de estratégia de apoio durante a exibição do filme.

Os estudos de Coutinho (2011), Calheiros e Fumes (2016) e Magalhães (2016) também apontaram a exclusão dos estudantes com deficiências por parte dos professores que ignoram suas necessidades específicas e se negam a adequar o material e/ou o método de avaliação conforme as características de seus alunos.

Ainda em relação às barreiras pedagógicas, vale mencionar que alguns estudantes disseram que a Universidade disponibilizou recursos materiais como mecanismo de apoio e que eles não foram eficazes. Como exemplo, foi indicado um programa que converte áudio em texto, mas o programa é on-line, e a fragilidade da internet na Universidade dificulta o uso do programa pela estudante. Outra estudante informou que a Universidade lhe emprestou um notebook, mas, como ela não tinha Internet em casa, não conseguia utilizar, conforme a fala ilustrativa a seguir:

Para entrarmos aqui é fácil, é que nem quando eu entrei na universidade e até não tinha falado isso, eles me arrumaram um computador da Universidade, só que eu vou ter que devolver quando acabar, mas eu não consegui usar porque agora que eu consegui internet, porque estou pagando, nós gastamos bastante [...]. (Grupo C)

O estudo de Magalhães (2016) também apontou que algumas estratégias propostas pela Universidade não foram bem sucedidas, ao fazer com que a própria estudante com deficiência estabelecesse mecanismos "para conseguir realizar os gráficos no computador, visto que os softwares de desenhos gráficos utilizados isoladamente não permitiam que a aluna tivesse compreensão total dos gráficos que foram gerados” (p. 85). 
Ainda sobre as barreiras pedagógicas, os acadêmicos também citaram o despreparo dos professores quanto à inclusão dos alunos com deficiências na Educação Superior, manifestado pela falta de adaptação da metodologia e do material de acordo com a necessidade específica.

O professor precisa ser preparado para ter um aluno especial na sala, porque preciso de uma prova específica, não tem para mim, minha prova diferenciada precisa ter letra ampliada, com mais tempo, aqui não tem [...]. (Grupo B)

Tem um professor que ele na prova dá 30 minutos, e é para todo mundo. Na última prova dele, ele queria que eu usasse o computador, eu não gosto porque força muito minha vista. Daí eu falei para ele me dar a prova ampliada, porque náo tinha condiçóes de eu fazer sem ampliar. Ele não gostou muito, mais aí ele saiu e, quando voltou, falou que não tinha como, e eu tive que usar a lupa, porque ele trouxe a prova com a letra normal, mas mesmo assim o tempo não dá. (Grupo C)

Nos estudos de Silva (2014), Poker et al. (2018) e Melo e Araújo (2018), os resultados indicaram o despreparo dos professores, os quais demonstraram não ter conhecimento suficiente sobre as necessidades específicas dos estudantes com deficiências.

Cabral e Melo (2017) expuseram dados quantitativos em relação à insuficiência do número de profissionais preparados para atender a esse público. Segundo relatos dos gestores dos núcleos participantes do referido estudo, 89\% deles informaram essa escassez, e ainda 63\% mencionaram a falta de sensibilização e de preparação dos docentes.

Drago (2010) e Coutinho (2011) também apontaram em seus estudos a falta de formação docente, em conjunto com a falta de estrutura física, de equipamentos e de recursos materiais, como fator influenciador em relação ao despreparo das Universidades para receber as pessoas com deficiências.

Muitos professores da Educaçáo Superior, embora tenham Mestrado e Doutorado, nem sempre tiveram uma formação pedagógica específica, como os professores da Educação Básica, que tiveram formação baseada nos cursos de Pedagogia e nas licenciaturas, com disciplinas específicas para a docência, conforme aponta o estudo de Santos e Fumes (2012). Para as autoras, esse processo de formação pedagógica da Educação Infantil à Educação Superior é importante para que os profissionais se preparem para a inclusão das pessoas com deficiências, de forma a implementar apoios pedagógicos necessários para que o aluno possa desenvolver suas potencialidades.

Ademais, percebe-se que os próprios professores não se sentem preparados, por não possuir qualquer formação específica para atender às necessidades específicas dos estudantes com deficiências em sala de aula (Drago, 2010; Moreira, 2010; Poker et al., 2018; Silva, 2013; Tartuci, 2014).

Em vista disso, as Instituiçóes devem organizar-se e adequar-se como um todo, de modo a extinguir as açóes excludentes e discriminatórias e favorecer a permanência e o aprendizado (Moreira, 2010). Também é preciso criar condiçóes favoráveis para possibilitar o sucesso acadêmico dos estudantes com deficiências.

Nesse contexto, é importante mencionar que, embora haja a presença de todas essas barreiras citadas que dificultam o ingresso e a permanência dos estudantes com deficiências, os 
participantes também reconheceram a existência de mecanismos facilitadores que permitiram tanto o acesso quanto a permanência e o sucesso desses acadêmicos na Educaçáo Superior.

\subsection{MeCanismos FaCILITADORES DA INCLUSÃo dOS ESTUdANTES COM DEFICIÊNCIAS NA EDUCAÇÁo SUPERIOR}

No que diz respeito à relação entre os estudantes com deficiências e os seus colegas, foi possível observar a presença, nos discursos, de relaçóes de amizade e de interaçóes com colegas sem deficiência estabelecidas durante o curso de Graduação - algumas no início e outras ao longo do curso - como facilitadores de permanência. Além disso, houve relatos de situaçóes nas quais os alunos com deficiências receberam apoio (inclusive emocional) e incentivo dos seus colegas de curso. Há a percepçáo de desenvolvimento dos próprios estudantes com deficiências, ao longo do curso, das habilidades relacionadas à socialização, o que facilitou a interação com os colegas universitários, conforme as falas a seguir:

E agora não, agora todo mundo está me respeitando bem, e eu gosto disso, que respeito gera isso [...]. (Grupo B)

Conforme o tempo vai passando e vão te conhecendo e ficando mais amiga, então hoje em dia eu não tenho tanto essa dificuldade, porque eu tenho as minhas amigas. Elas sempre me colocam no grupo quando tem trabalho, e sempre nós nos sentamos juntas. (Grupo C)

Então, meus amigos têm cuidado comigo fora da sala de aula, dentro da sala de aula, qualquer dificuldade que eu tenho eles têm atenção em dobro. [...] tenho muitos amigos, e me sentar entre eles me ajuda muito [...]. (Grupo E)

Os resultados dos estudos conduzidos por Castro (2011), Coutinho (2011), Nantes (2012), Tartuci (2014) e Calheiros e Fumes (2016) também apontaram como facilitadores de permanência as relaçóes de amizade com os demais colegas e os professores, as quais também aconteceram e se estabeleceram durante o percurso acadêmico, resultando em mudança de comportamento e de prática pedagógica além de propiciar a participação dos estudantes com deficiências.

No que se refere às estratégias de apoio direcionadas aos alunos com deficiências na Universidade, alguns participantes citaram a oferta e a disponibilização, por parte da Instituição, de recursos de acessibilidade como facilitadores de sua permanência, como, por exemplo: acesso à sala de aula, softwares, mobiliário adequado, materiais digitalizados, provas ampliadas, gravação das aulas, lupa de aumento e carro para cadeirante, como mostram as falas a seguir:

Eu comprei um notebook, porque na faculdade você não vive sem um, e eu e a técnica administrativa do núcleo quebramos muito a cabeça para baixar aqueles aplicativos, o NVDA, e tem um outro, o DosVox, que ele lê para mim os textos em PDF. Os aplicativos me ajudam muito, aí tem a mesa na minha sala com a minha cadeira, tem a luminária e aquele outro, o plano inclinado [...]. (Grupo A)

Eu pedi também o programa, o leitor de tela para eu escrever no laboratório. Fui bem atendido. Tem duas máquinas que têm esse programa, que não atrapalha em nada, eu dou o comando, e ele abre né. Eu pedi que mandassem esse computador no laboratório de acessibilidade e me atenderam de pronto [...]. (Grupo B) 
O apoio que eu tenho aqui é a sala de acessibilidade, que é representada por dois professores. Quando os professores mandam e-mail, mandam para mim ou para o professor da sala de acessibilidade. Eles escaneiam os livros e me mandam [...]. E aqui na universidade eu faço as provas no computador e eu tenho uma técnica de estudo junto com meus professores. Eles trazem o pen drive já com o arquivo da prova e eu respondo, faço toda a prova, salvo e devolvo o pen drive [...]. (Grupo B)

Eu fui, e eles me deram uma régua que é uma lupa que eu uso também e as provas ampliadas. Às vezes eu tiro foto na aula do que eu preciso, para não forçar muito. (Grupo C)

Nos estudos de Castro e Almeida (2014), Ciantelli e Leite (2016) e Magalhães (2016), os resultados também indicaram a presença de acessibilidade física e/ou metodológica como mecanismos facilitadores. Como exemplo, foram mencionados: a adaptação e a flexibilização curricular, a adaptaçáo de provas, a digitalização de materiais, o uso de gravadores, a utilização de materiais ampliados, softwares e mobiliário adequado e a viabilização do acesso à sala de aula.

Além disso, os participantes da pesquisa relataram que contam com o apoio de recursos humanos, com professores de apoio, intérpretes e monitores, como agentes facilitadores de sua permanência.

Em 2016, eu peguei uma professora de apoio; em 2017, eu peguei outra que é a que está comigo até o momento [...]. (Grupo C)

E na universidade, eu recebo mais o apoio dos professores, eles mandam os conteúdos no meu e-mail, eu tenho duas monitoras que me ajudam, com esse encaminhamento de textos, e outra na questão de fazer atividade, de fazer prova, então eu tenho sim o apoio no meu curso. [...] aí estou com o apoio que está esse ano também [...]. (Grupo C)

Eu tenho intérprete. Por exemplo, também tem outras funçôes que os intérpretes me aconselham bastante sobre a minha vivência aqui na universidade [...]. (Grupo D)

Fato semelhante foi registrado no estudo de Ciantelli e Leite (2016). Segundo os resultados descritos no referido estudo, algumas açóes dos núcleos favoreceram a acessibilidade comunicacional, com a disponibilização de tradutores/intérprete de LIBRAS, de monitores/ bolsistas e do guia-intérprete. Os resultados do estudo conduzido por Nozu et al. (2018) apontaram índices quantitativos quanto à disponibilização de intérprete de LIBRAS e de guia-intérprete. Acima de $97 \%$ dos cursos na Universidade de Brasília (UnB) e de $71 \%$ na Universidade Federal de Goiás (UFG) contam com esse apoio, e, com baixa frequência, os cursos da UFGD e da UFMS.

Além disso, o papel dos gestores das Universidades também foi mencionado como parte dos mecanismos favorecedores da inclusão das pessoas com deficiências no ambiente universitário. Em uma das universidades investigadas, o gestor organizou um evento, com a participação de convidados externos, que consistiu em uma discussão sobre acessibilidade na Educação Superior, de acordo com as falas a seguir:

Procurei a coordenadora do meu curso. Olha, é um amor de pessoa, ela me ajudou muito, ela que me ajudou mesmo, olha, vamos ali, vamos aqui, você vai responder às perguntas [...], ela buscou os professores [...]. (Grupo A) 
Em relação ao apoio, onde eu fui buscar ajuda e informações, sempre fui bem atendida, me receberam bem, fui bem informada [...]. (Grupo A)

Esses dias atrás, à noite, né, o diretor fez uma roda de conversa sobre acessibilidade, trouxe umas pessoas de fora, inclusive eu contei a minha história [...]. (Grupo B)

$\mathrm{Na}$ coordenação, tem pessoas que me ajudam, tem pessoas boas. A maior dificuldade que eu senti foi com os colegas e com os professores. (Grupo C)

Ciantelli e Leite (2016) e Ciantelli et al. (2017) também mencionam, em seus estudos, algumas ações dos núcleos, como formação e sensibilização da comunidade acadêmica em relação às necessidades específicas dos estudantes com deficiências. Por outro lado, Magalhães (2016) apontou o relato de uma estudante com deficiência sobre a falta de conhecimento de alguns coordenadores em promover a inclusão desses estudantes na Educação Superior.

Por sua vez, no que diz respeito à ação docente, percebeu-se nos relatos dos participantes que muitos professores estáo conscientes sobre o processo de inclusão dos estudantes com deficiências. Tal conscientização é demonstrada pela atitude atenta frente às demandas do público em questáo, pelo acolhimento na busca por conhecimento, pelo planejamento e pela implementaçáo de estratégias de ensino e de aprendizagem capazes de atender às necessidades específicas desse público.

Aquele professor que sabe que você tem uma deficiência, eu vou citar uma professora que eu amo de paixão. Antes de eu chegar na faculdade, ela já mandou todo o meu material ampliado. Então, na sala, eu sempre venho empolgada, eu venho com aquela vontade de realizar aquilo, porque eu tenho ajuda [...]. (Grupo A)

Assim, os professores, acho que têm até uma boa vontade, eles conversaram comigo em relação às adaptaçóes, como é que eu prefiro. Tudo isso foi conversado comigo, demorou um ano, mas o importante é que vieram, eu náo tenho nenhum problema. Os professores tentam me ajudar da melhor forma que eles podem, fazem até o impossível [...]. (Grupo B)

$\mathrm{Na}$ faculdade alguns professores às vezes me dão uma prova ampliada. [...] tem professores bons, tem uma professora mesmo que ela é muito legal, ela traz ampliado para mim, ela traz tudo certinho, o coordenador já pediu para os professores [...]. (Grupo C)

No estudo de Poker et al. (2018), essa atitude de acolhimento e de busca de estratégias também foi apontada, quando o professor mencionou que se coloca à disposição do aluno para ajudá-lo por meio do diálogo. Torna-se evidente que os professores estáo aprendendo sobre como promover a inclusão na Educação Superior e, nesse processo, algumas vezes, buscam construir estratégias junto aos próprios universitários com deficiências. Nesse sentido, o estudo de Magalhães (2013) sugere o trabalho em conjunto entre professores e alunos, em constantes diálogos, em busca de estratégias para a formulação de adaptação de material e de meios para avaliar a aquisiçáo do conhecimento em sala de aula.

É imprescindível abordar mais um importante facilitador citado pelos participantes do estudo: o apoio familiar. Alguns participantes relataram a importância do apoio familiar (pais, esposos, filhos, irmãos e amigos próximos) como um facilitador tanto para seu ingresso quanto para sua permanência na Educação Superior, de acordo com as falas a seguir: 
Minha irmã e minha mãe vieram pedir apoio no primeiro dia de aula. (Grupo A)

Aí quando eu fui fazer a minha inscrição, eu vim com o meu esposo, mas com medo, com vergonha, ele me incentivando [...]. (Grupo B)

E quando eu fiz esse reagendamento da matrícula, quem me ensinou e me trouxe para a faculdade foi o meu pai. Eu tive esse apoio da minha família. (Grupo B)

Fora do âmbito da faculdade, minha família mesmo, minha irmã, quando eu não conseguia ler, ela fazia os trabalhos manuais para mim, lê o que eu não consigo e transcreve também. (Grupo E)

No estudo de Coutinho (2011), também foi evidenciado o apoio da família como um facilitador para a inclusão e a participação dos estudantes com deficiências. Por outro lado, Cabral e Melo (2017) apresentaram dados quantitativos em relação à falta de apoio familiar, em que $35 \%$ dos gestores informaram que as famílias dos estudantes com deficiências não auxiliavam nesse processo.

Outro aspecto identificado nos relatos dos participantes foi o importante papel desempenhado pelo núcleo e/ou setor responsável pela acessibilidade, avaliado por todos os participantes como o principal facilitador para a permanência das pessoas com deficiências nas universidades, de acordo com a fala a seguir:

Bom, a Universidade em si ela não ajuda, se não fosse o núcleo, todo mundo estava, no sentido figurado, estava ferrado [...]. (Grupo A)

No estudo de Castro (2011), o núcleo e/ou setor responsável pela acessibilidade foi apontado como facilitador mais recorrente nos relatos sobre os serviços de apoio. De fato, muitas questôes envolvem a acessibilidade das pessoas com deficiências na Educação Superior. Neste estudo, os participantes demonstraram conhecer suas necessidades e, inclusive, indicaram caminhos para supri-las.

Nesse sentido, os participantes solicitaram: oferta da disciplina de Educação Especial para todos os cursos, para ampliar o conhecimento dos profissionais em formaçáo sobre as pessoas com deficiências, suas limitaçóes e suas necessidades; formação continuada aos professores universitários sobre questóes relacionadas aos estudantes com deficiências; oferta de cursos e disciplinas optativas (como cursos de oratória, de língua portuguesa, de interpretaçáo de texto, de LIBRAS, de técnicas de seminário, além de orientaçóes sobre como escrever um artigo e como fazer um relatório) capazes de contribuir para a participaçáo e o aprendizado dos acadêmicos nas disciplinas obrigatórias que compóem a matriz curricular de seus cursos, conforme apontam as falas a seguir:

Então, acho que seria legal ter cursos não só para nós que somos especiais, para todo mundo, para conseguir entrar nesse universo que é o universo acadêmico. (Grupo A)

Grupos de estudos [...], que nem eles falaram do curso de oratória, que seria muito bom, um curso ou minicurso, alguma coisa seria bem interessante. Olha, eu sugiro comportamento humano [...] e aí técnicas de seminário, para pessoas que não têm deficiência, não só para pessoas que tem deficiência [...]. (Grupo A) 
Além disso, os participantes manifestaram a necessidade de flexibilização curricular no que diz respeito ao tempo para cursar disciplinas ou realizar as atividades propostas, assim como a adequação de conteúdo, de estratégias pedagógicas e de formas de avaliação.

\section{Conclusóes}

Os resultados identificaram que os estudantes com deficiências encontram importantes mecanismos facilitadores para sua permanência na Universidade, tais como: softwares, apoio de ledor/transcritor, intérprete de língua de sinais, monitoria, material ampliado, adaptação de materiais, material digitalizado, mobiliário adequado e/ou acessibilidade arquitetônica (sala acessível), gravação das aulas, lupa de aumento, carro para cadeirante, relaçóes de amizade entre os estudantes com deficiências e os demais colegas, atitude positiva do professor em prol da inclusão dos universitários com deficiências, núcleo e/ou setor de acessibilidade e o apoio dos familiares.

Além dos facilitadores, também foram identificadas barreiras presentes no cotidiano universitário dos estudantes com deficiências que dificultam e/ou impedem seu processo de inclusão na Educação Superior, como: arquitetônicas, urbanísticas, atitudinais, comunicacionais, de informação e pedagógicas.

Nesse contexto, é preciso reconhecer, porém, que há dificuldade de implementação das orientaçôes normativas nas instituições, pela ausência de estrutura física, pela ausência de recursos humanos e materiais, pela presença de atitudes excludentes motivadas pela falta de conhecimento e pela falta de formação docente para atuar com pessoas com deficiências. Percebe-se, ainda, que a burocracia dificulta que os recursos sejam disponibilizados para dar continuidade às adequações necessárias para a implementação das políticas inclusivas.

Frente às informaçóes apresentadas, colocam-se os seguintes questionamentos: 1) Considerando que os professores, em geral, não apresentam conhecimento suficiente sobre as características e as necessidades dos estudantes com deficiências, como as adequaçóes necessárias e a flexibilização curricular serão implementadas?; 2) Quais mecanismos estão sendo colocados em prática pela Universidade para que as barreiras pedagógicas possam ser superadas? Os resultados são denunciadores, pois constatou-se que, de modo geral, os estudantes com deficiências continuam invisibilizados na Universidade. As barreiras apontadas indicam que a inclusão das pessoas com deficiências na Educação Superior exige atenção, reflexão, ação e investimento da comunidade acadêmica, assim como dos governantes.

Os resultados sinalizam também que os participantes avaliaram que o núcleo e/ou setor responsável pela acessibilidade não é suficiente para promover a inclusão dos estudantes com deficiências. Eles defendem a necessidade de maior envolvimento de outros profissionais para complementar a sua formação. Tendo em vista tal apontamento, é pertinente o questionamento sobre qual é o papel do núcleo e/ou setor responsável pela acessibilidade. Em decorrência dessa pergunta, outras se fazem necessárias: 1) Quais são as atribuiçôes do gestor do núcleo e/ou setor responsável pela acessibilidade frente ao processo de inclusão dos alunos com deficiências na Universidade?; 2) Quem será responsável por isso?; 3) É papel do coordenador do núcleo chamar aluno por aluno e resolver o problema dele?; 4) E se esse mesmo coordenador faltar um dia, quem assumirá essa responsabilidade? 
Considerando todas as barreiras identificadas neste estudo, assim como os mecanismos facilitadores existentes, é possível argumentar que o núcleo e/ou setor responsável pela acessibilidade não deve assumir de forma isolada o protagonismo pelas açóes voltadas a eliminar e/ou a diminuir barreiras e também para promover a participação, a permanência e a formação dos estudantes com deficiências. Defende-se que caberia ao núcleo e/ou setor responsável pela acessibilidade o papel de mediar tais ações, empoderando todos os atores envolvidos diretamente com o processo de inclusão na Educação Superior, ou seja, acadêmicos, professores, gestores, técnico-administrativos, familiares, entre outros.

Em vista disso, uma ação centrada apenas no aluno é considerada uma visão biocentrada, que concentra no estudante as explicaçôes para todas as dificuldades encontradas durante o processo de escolarização. Por isso, ao propor qualquer tipo de intervenção, o aluno é ajustado para que consiga se adequar à Universidade. No entanto, acredita-se que a Universidade deve adequar-se ao aluno; desse modo, a Universidade precisa modificar-se, transformar-se.

Por fim, cabe destacar que a discussão dos resultados desta pesquisa não almejou esgotar todas as questóes que envolvem o tema, mas promover uma reflexão acerca de algumas questóes específicas, presentes no cotidiano dos alunos com deficiências, como as barreiras e os facilitadores encontrados para o ingresso, a permanência, a formação e o sucesso acadêmico, a partir dos relatos dos próprios estudantes sobre as vivências e os anseios em relação à sua inclusão na Educação Superior.

Como indicaçóes para futuros estudos, sugerem-se pesquisas voltadas à descrição e à análise de formas capazes de potencializar as relaçóes entre os estudantes com deficiências e seus colegas universitários. Além disso, recomenda-se a realização de estudos que visem, por meio da pesquisa colaborativa, promover estratégias pedagógicas a serem implementadas na Educação Superior com base na consultoria colaborativa escolar.

\section{REFERÊNCIAS}

Almeida, J. G. A., \& Ferreira, E. L. (2018). Sentidos da inclusão de alunos com deficiência na educação superior: olhares a partir da Universidade Federal de Juiz de Fora. Psicologia Escolar e Educacional, 22(esp.), 67-75. https://doi.org/10.1590/2175-3539/2018/047

Cabral, L. S. A., \& Melo, F. R. L. V. (2017). Entre a normatização e a legitimação do acesso, participação e formação do público-alvo da educação especial em instituiçôes de ensino superior brasileiras. Educar em Revista, 33(esp. 3), 55-70. https://doi.org/10.1590/0104-4060.41046

Calheiros, D. S., \& Fumes, N. L. F. (2016). A inclusão de universitários com deficiência em cursos de Educação Física na cidade de Maceió/AL. Avaliação, 21(2), 523-539. https://doi.org/10.1590/ S1414-40772016000200011

Cantorani, J. R. H., \& Pilatti, L. A. (2015). Acessibilidade na Universidade Tecnológica Federal do Paraná: análise a partir de relatórios do Inep e do olhar do gestor. Educar em Revista, 57, 171-189. https://doi.org/10.1590/0104-4060.41363

Castro, S. F. de. (2011). Ingresso e permanência de alunos com deficiência em universidades públicas brasileiras [Tese de Doutorado, Centro de Educação e Ciências Humanas, Universidade Federal de São Carlos - UFSCar]. Repositório Institucional da UFSCar. https://repositorio.ufscar.br/bitstream/handle/ ufscar/2878/3611.pdf?sequence $=1$ \&isAllowed $=y$ 
Castro, S. F., \& Almeida, M. A. (2014). Ingresso e permanência de alunos com deficiência em universidades públicas brasileiras. Revista Brasileira de Educação Especial, 20(2), 179-194. https:// doi.org/10.1590/S1413-65382014000200003

Ciantelli, A. P. C., \& Leite, L. P. (2016). Açóes exercidas pelos Núcleos de acessibilidade nas universidades federais brasileiras. Revista Brasileira de Educação Especial, 22(3), 413-428. https://doi.org/10.1590/ S1413-65382216000300008

Ciantelli, A. P. C., Leite, L. P., \& Nuernberg, A. H. (2017). Atuação do psicólogo nos "núcleos de acessibilidade" das universidades federais brasileiras. Psicologia Escolar e Educacional, 21(2), 303311. https://doi.org/10.1590/2175-3539201702121119

Coutinho, M. M. A. (2011). A inclusão da pessoa com deficiência visual na Educação Superior e a construção de suas identidades [Dissertação de Mestrado, Programa de Pós-Graduação em Educação, Universidade Católica Dom Bosco - UCDB]. Repositório Institucional da UCDB. https://site. ucdb.br/public/md-dissertacoes/8200-a-inclusao-da-pessoa-com-deficiencia-visual-na-educacaosuperior-e-a-construcao-de-suas-identidades.pdf

Cury, C. R. J. (2005). Os fora de série na escola (1ª ed). Autores Associados.

Decreto $n^{\circ}$ 6.949, de 25 de agosto de 2009. Promulga a Convenção Internacional sobre os Direitos das Pessoas com Deficiência e seu Protocolo Facultativo, assinados em Nova York, em 30 de março de 2007. http://portal.mec.gov.br/dmdocuments/decreto6949_seesp.pdf

Drago, R. (2010). A inclusão chega ao ensino superior: concepçóes inclusivistas de um grupo de profissionais de uma faculdade privada da Grande Vitória. In S. L. Victor, R. Drago, \& J. F. Chicon (Eds.), A educação inclusiva de crianças, adolescentes, jovens e adultos: avanços e desafios (1 ${ }^{\mathrm{a}}$ ed., pp. 273-302). Edufes.

Garcia, R. A. B., Bacarin, A. P. S., \& Leonardo, N. S. T. (2018). Acessibilidade e permanência na Educação Superior: percepção de estudantes com deficiência. Psicologia Escolar e Educacional, 22(esp.), 33-40. https://doi.org/10.1590/2175-3539/2018/035

Lei $n^{\circ}$ 13.146, de 6 de julho de 2015. Lei Brasileira de Inclusão da Pessoa com Deficiência (Estatuto da Pessoa com Deficiência). http://www.planalto.gov.br/ccivil_03/_ato2015-2018/2015/lei/113146.htm

Magalhães, R. C. B. P. (2013). Currículo e inclusão de alunos com deficiência no ensino superior: reflexôes sobre a docência universitária. In F. R. L. V. de Melo (Ed.), Inclusão no ensino superior: docência e necessidades educacionais especiais ( $1^{\mathrm{a}} \mathrm{ed}$., pp. 47-55). Edufrn.

Magalhães, R. L. (2016). Acessibilidade de universitário com baixa visão no uso de software de desenhos gráficos em duas disciplinas na UnB [Dissertação de Mestrado, Programa de Pós-Graduação em Educação, Universidade de Brasília - UB]. Repositório Institucional da UB. https://repositorio. unb.br/handle/10482/21149

Martins, N. S. C. (2016). Os desafios e as possibilidades do trabalho docente no ensino e aprendizado do aluno surdo na universidade [Dissertação de Mestrado, Programa de Pós-Graduação em Educação, Universidade Católica Dom Bosco - UCDB]. Repositório Institucional da UCDB. https://site. ucdb.br/public/md-dissertacoes/19477-nayara-cesario-martins.pdf

Melo, F. R. L. V., \& Araújo, E. R. (2018). Núcleos de acessibilidade nas universidades: reflexóes a partir de uma experiência institucional. Psicologia Escolar e Educacional, 22(esp.), 57-66. https:// doi.org/10.1590/2175-35392018046 
Moreira, L. C. (2010). Práticas Pedagógicas na universidade e alunos com necessidades educacionais especiais: entre desafios e buscas. In S. L. Victor, R. Drago, \& J. F. Chicon (Eds.), A educação inclusiva de crianças, adolescentes, jovens e adultos: avanços e desafios (1 $1^{\mathrm{a}} \mathrm{ed} ., \mathrm{pp}$. 303-316). Edufes.

Morgan, D. (1997). Focus group as qualitative research. Qualitative research methods series. Sage Publications.

Nantes, J. de M. (2012). A constituição do intérprete de Lingua de Sinais no Ensino Superior na perspectiva dos surdos: o cuidado de si e do outro [Dissertação de Mestrado, Programa de Pós-Graduação em Educação, Universidade Federal da Grande Dourados - UFGD]. Repositório Institucional da UFGD. https://repositorio.ufsc.br/bitstream/handle/123456789/190447/NANTES\%20 Janete\%20de\%20Melo\%202012\%20\%28disserta\%c3\%a7\%c3\%a3o\%29\%20UFGD. pdf? sequence $=1$ \&isAllowed $=y$

Nozu, W. C. S., Silva, A. M., \& Anache, A. A. (2018). Permanência do aluno com deficiência no ensino superior: dados censitários sobre as universidades federais da regiáo centro-oeste. Revista IberoAmericana de Estudos em Educação, 13(esp. 2), 1421-1435. https://doi.org/10.21723/riaee.v13. nesp2.set2018.11652

Poker, R. B., Valentim, F. O. D., \& Garla, I. A. (2018). Inclusão no ensino superior: a percepção de docentes de uma instituição pública do interior do estado de São Paulo. Psicologia Escolar e Educacional, 22(esp.), 127-134. https://doi.org/10.1590/2175-3539/2018/010

Santos, S. D. G., \& Fumes, N. de L. F. (2012). A inclusão da pessoa com deficiência na Educação Superior: um olhar sobre formação e a prática docente. In E. G. Mendes, \& M. A. Almeida (Eds.), Dimensóes Pedagógicas nas Práticas de Inclusão Escolar (1a ed., pp. 109-126). Abpee.

Silva, J. O. (2014). Açôes inclusivas no ensino superior brasileiro. Revista brasileira Estudos pedagógicos, 95(240), 414-430.

Silva, J. S. S. da, \& Ferreira, W. B. (2017). Sombreando a pessoa com deficiência: aplicabilidade da técnica de sombreamento na coleta de dados em pesquisa qualitativa. Revista Brasileira de Educação Especial, 23(2), 185-200. http://dx.doi.org/10.1590/s1413-65382317000200003

Silva, L. G. S. (2013). Orientaçôes didáticas para atuação pedagógica junto a estudantes com deficiência visual, no ensino superior. In F. R. L. V. de Melo (Ed.), Inclusão no ensino superior: docência e necessidades educacionais especiais ( $1^{\text {a }}$ ed., pp. 57-82). Edufrn.

Tartuci, T. M. (2014). Ingresso e permanência de alunos com deficiência na UFG/Campus Catalão [Dissertação de Mestrado, Programa de Pós-Graduação em Educação, Universidade Federal de Goiás - UFG]. Sistema de Biblioteca da UFG. https://repositorio.bc.ufg.br/tede/handle/tede/3924

Recebido em: 12/05/2020

Reformulado em: 16/11/2020

Aprovado em: 22/11/2020 